\title{
Brand Personification: A Study on Humanizing Personal Care Products in Sri Lanka
}

\author{
A.A.S.N Munasinghe ${ }^{1,2}$ \\ ${ }^{1}$ Sri Lanka Institute of Marketing, Colombo, Sri Lanka \\ ${ }^{2}$ Sri Lanka Institute of Information Technology, Colombo, Sri Lanka \\ Correspondence: A.A.S.N Munasinghe, Sri Lanka Institute of Information Technology, Colombo, Sri Lanka.
}

Received: December 7, 2018

Accepted: January 7, 2019

Online Published: January 11, 2019

doi:10.5539/ibr.v12n2p21

URL: https://doi.org/10.5539/ibr.v12n2p21

\begin{abstract}
In the context of marketing communications where the concern is to create effective brand promotions, associating a brand with the personality of the consumers commonly known brand personification has become one of the most prominent aspects over recent years. In the process of designing the message, incorporating an appeal where the brand is associated to a human-like character is called the humanization of brands in advertising. There, the brand focuses on attracting the consumers with a reflection of the consumer's personality in the brand being promoted. This strategy becomes thousand times more attractive to those products which are closely associated with the consumers. Thus, humanizing a brand alone isn't sufficient, while humanizing them in the appropriate appealing manner is much more vital. Hence, this research will mainly be focusing on identifying the most suitable personality dimension to be associated for some of the top of mind personal care brands in Sri Lanka. The research approach, which takes the form of both quantitative and qualitative follows the use of multiple sources of data collection methods. The qualitative aspect clarifies the initial stage with the identification of the top of mind personal care brands and the personality dimensions which are closely associated with the targeted group. The quantitative aspect of the study is satisfied via the data gathered through a self-administered questionnaire developed by the researcher. The study then focuses upon an in-depth statistical analysis with the application of the Kruskal Wallis H Test followed by the Nemeyni Post Hoc test to identify the most suitable personality dimension to be associated with each brand in the humanizing them. The findings reveal some interesting facts over the consumer's preferred dimensions to be reflected on those brands.
\end{abstract}

Keywords: brand personification, personality, humanization of brands, personal care products

\section{Introduction}

From a marketing communications perspective, the marketers are faced with the challenge of designing promotions which are not only attractive, but appealing too. In this context, making it appealing involves putting an effort to differentiate the offering in a unique way, not only for it to be preferred, but to be preferred and picked over the competitive offerings as well. Brand personality serves as a differentiator, giving competitive edge to the marketers. In a world, where the competitors can easily copy features and price, the associated personality cannot be or can minimally be duplicated. By creating a favorable and a liked brand personality, it helps to set the brand apart. Brand Personality, also serves as a liability in building and maintaining the corporate image. The failure or inability to maintain a favorable brand image that would match and appeal to the consumers in the best possible way will ultimately, result in a loss of interest by the consumers in products, resulting them to move in to alternatives.

\subsection{Current Situation of the Study and the Problem Statement}

In Sri Lanka, a wide variety of personal care brands are available from a number of different manufacturers. Among them, the highest number of personal care brands are manufactured and marketed by Unilever Sri Lanka and Hemas Holdings. The personal care products, which comes under the "Fast and quick to leave" category commonly known as Fast Moving Consumer Goods (FMCG), consist of some other product categories as well. These personal care products can again be classified in to skincare, haircare, fragrances, cosmetics and oral care products. According to the data published in LMRB household panel, Unilever Sri Lanka owns the highest number of brands in each category. Accordingly, the marketing communication specific budgetary allocations for 
this product category compared to the other categories also remain to be the largest (Cooray, 2016). Hence, making the best use of such investments is of utmost importance by creating a positive impact on the sales. For this purpose, the role played by the communications is to be assessed as it serves as a prime factor in affecting the ultimate purchase decision of the customers.

With the intention of deepening the understanding on this, a mini-survey conducted by the researcher reveals that majority of the female consumers prefer to see the their personality being reflected in the personal care brands they consume the most. The reason or the justification was cited as those products being personally attached to them.

This finding was also confirmed by (Maehle \& Shneo, 2010), stating that the consumers tend to prefer and purchase brands which matches with their personality which has a congruence with their own self-concept. Thus, it can be noted that the requirement isn't always about creating a personality for a brand, but associating it with a human personality which would match. Therefore, the marketers face the challenge of creating appealing communications to the customers, which goes in line with the target audience's personality. The importance does not only lie in creating a strong brand personality, but to create a personality which matches and fits its users while appealing them. Hence, the marketers are faced with the requirement of creating a brand personality which goes in line with the personality of the target audience.

\subsection{The Objectives of the Study}

With the focus upon that, this study will be aiming to identify the most appropriate personality specific dimension to be highlighted in a selected number of brands. The particular objective is fulfilled by identifying the personal care product types in the Sri Lankan FMCG industry followed by the identification and of the dimensions brand personality first.

Due to the inability of dealing with a large scope, as there are over 200+ personal care brands are available in Sri Lanka, top of mind brand from each category was chosen to carry out the study.

\section{Literature Review}

On the base of animism, the brands possess unique personalities on their own (Dolatabadi, Kazemi, \& Nima, 2012). Similarly, the human's conscious as well as the subconscious mind feels a need as in personifying the objects to interact with the intangible world. Therefore, it is considered that most of the direct and interactions that the consumers have with a brand can affect the perceptions on personality (Plummer, 1984). It makes it convenient for consumers to connect with personality as opposed to a claim or a benefit in becoming familiarized with a brand. This becomes more import in the context if the brand is specifically something which is personally attached to a person. Thus, personification gives brands a unique identity, and enables the consumers to build relationships with them (Bensi, 2015).

In the context of creating advertisements for a brand, an interesting concept utilized by the modern marketers in attempting to put the consumer's perception of a brand in to a human -based character. Thus, it ends up giving a personality to the brand. In terms of associating the personality, the brand is assumed to be a person and it is known as brand personification (Aaker, 1997).

On top of that, it is accepted by many that the consumers tend to be receptive and responsive towards those communications delivered via a spokesperson who has a emotional bond with the buyer, over a person who does not have (Santos, 2014). Similarly, the brands are also capable of forming similar relationships with the consumers through their adaptation of human behavior and characteristics which ultimately results in a better receptive nature and responsiveness. From the consumer's point of view, brand personification is important for them in as they consider the possessions they own as a part of themselves. Majority, relate their self and identity partially in the products that they purchase and what those goods symbolize. Some people also associate their self-worth in terms of the above discussed associations. 
Aaker (1997) defines the distinct characteristic of brand personality as follows,

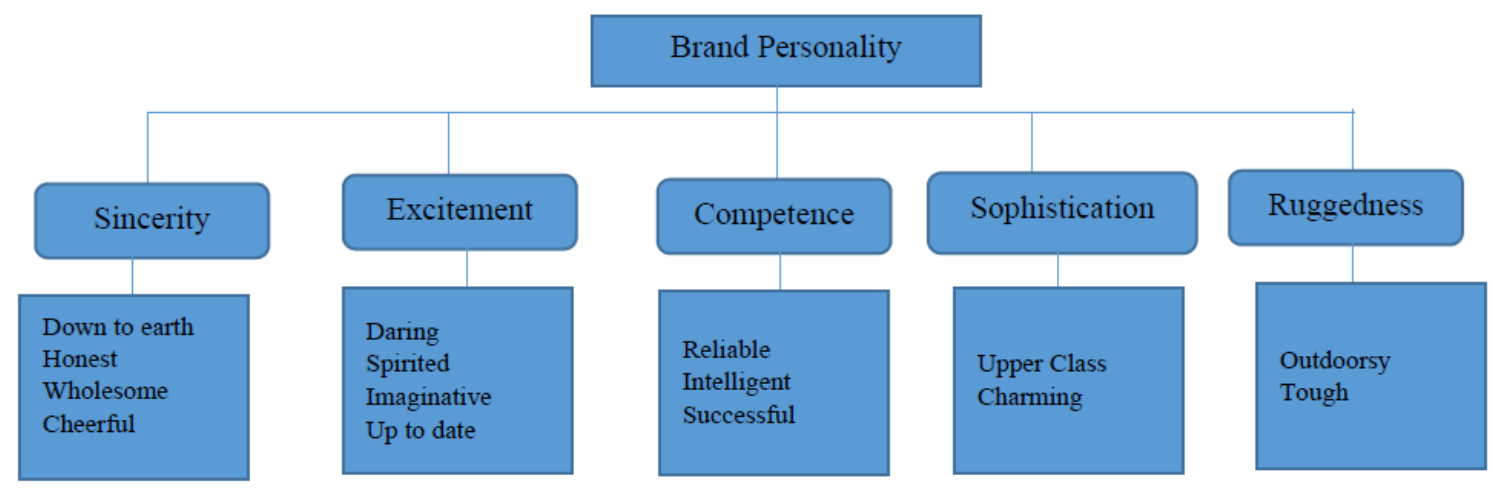

Figure 1. Brand Personality Framework Source: (Aaker, 1997)

A brand would acquire such a profile with the associations created through an advertisement including the users associated with that product or the endorsers involved in promotions (Monger, 2012).

In spite of being largely characterized by the personality traits, the feelings are also reflected in the brand personality. Aaker 1997, states that the consumer's attitudes and behavior which is connected with the brand preference followed by a purchase decision is moderated with the presence of a favorable personality. For example, if there that is a person who is adventurous and excitable, it is most likely to associate that person with a feeling of urgency or excitement. On the other hand, the purchase or consumption of another band could be associated with feelings such as security and calmness.

It is also considered that, brand personality aids in creating an association of the brand with important life values. For example, those values are concerned with an excitement in life, self-respect, self-expression etc. since the individuals have distinguishing traits which are different from one another, the values they hold also differs accordingly. Therefore, a brand which is capable of getting itself a distinctive personality, may get highly attached with a certain value, and will eventually attract people who admire that value.

This concept is ultimately concerned with creating a better understanding of the brands with the consumers, and then maintaining a healthier relationship between brands and consumers. Aaker (1997) further states that the consumer attitudes and behaviors are actually a reflection of Brand personality, which ultimately gets connected with the purchase intention of the consumer through the brand preference being created.

A study on "sincerity, sophistication and excitement: The different effects of perceived brand Personality on brand extension evaluation reveals that the brand building process and brand personality shaping, the selection of what sort of a personality to be shaped, is considered as a prime factor on most of the long term marketing objectives $(\mathrm{He}, 2012)$. In this entire process of defining themselves, the consumers choose brands which have a brand personality that is congruent with the self-concept which is one's own definition of their self (Dolatabadi, Kazemi, \& Rad, 2012).

A study on "Congruence between brand and human personalities" reveals that the congruity between brand and the user's self-image acts as a motivational factor in consumer preference and choice. The findings elaborate that, excitement, sophistication and ruggedness seem of utmost importance in brand personality over the other as the consumers prefer brands with those personality traits over sophistication and excitement. It is further noted that greater the intensity of personal expression in brands, higher the probability towards a purchase intention through a brand preference (Maehle \& Shneo, 2010).

Hence, with the understanding of the above context, the markets are encouraged to contact with the customers through the personality, by building a personality to their brands which matched consumer's personal traits that helps the consumer's in quickly preferring those brands (Banerjee, 2016).

A consumer's preference towards a brand is reflected through the personality in most of the instances (Banerjee, 2016). This relationship is supported by few theorists as it was also found that the consumers do not merely purchase brands for the sake of functional benefits. Thus, the purchase is also driven with preference to display their identities. With reference to the same reason, the consumers tend to prefer brands as they feel them to be matched or consistent with their personalities (Banerjee, 2016). Thus, it is said that the consumers prefer a brand, when they see themselves in it. Hence brand preference is consistent with consumer personality to a greater extent (Aaker, 1997). At the same time, theorists such as Mulyanegara, Tsarenko, Anderson (2009) had found a significant relationship between the five dimensions of the Aaker's brand personality model and brand 
preference (Banerjee, 2016).

A study on consumer perception and brand personality traits for making cosmetic purchases has revealed that consumer's involvement towards the brand in terms of preference and purchase is highly influenced by the personality traits associated with a brand (Gupta, 2013). Thus, further revelations were made in terms of the moderating effect of consumer perception as well.

Thus, it can be said that in the current context, people do not purchase products for mere consumption and the capabilities, but for also their representation and symbolization and the symbolic qualities (Jinsu,2014).

\section{Methodology}

This research follows a mixed-method with the incorporation of both qualitative and quantitative approaches. The study commenced with a qualitative approach to deepen up the understanding of the study area followed by a quantitative approach to measure the various views and opinions.

\subsection{Sample Population}

As a result of the emerging lifestyles of people, personal care product belongs to a considerable and a major portion of non- food related expenditures of the Sri Lankans (The Central Bank of Sri Lanka, 2017). By considering the demographic figures across Sri Lanka, female consumers born in 1980s and 1990s were considered as being a significant group to engage with. These young adults consisting about 3.5 million strong and their expenditures on personal care products showed a rapid growth (The Nielsen Company, 2017). Therefore, the target population considered had females aged 20-35. The population was narrowed down further via a sample chosen through the convenient sampling technique.

\subsection{Sample}

Since the study initially commenced with the intention of deepening the understanding on the study area and to choose the top of mind brands. Three Focus Group Discussions (FGD's) having 5 members in each was conducted. To ensure the consistency of the findings via the homogeneity of the group, female personal care consumers aged in between 16-30 was included in the discussions.

Once the top of mind brands was finalized through the FGD's, those findings were incorporated to design the structured questionnaire to be distributed among the target sample. Once, this data collection instrument was finalized, it was distributed to 200 female consumers of the same target population as described above through the convenient sampling technique. This, marked the utilization of the quantitative data gathering aspect of the study. Those were then quantified and analyzed with the statistic-based methods to come up with a conclusion in choosing the most appropriate personality dimension.

The entire data collection procedure can be aligned with the overall objective of the study as follows,

Table 1. Data collection procedure

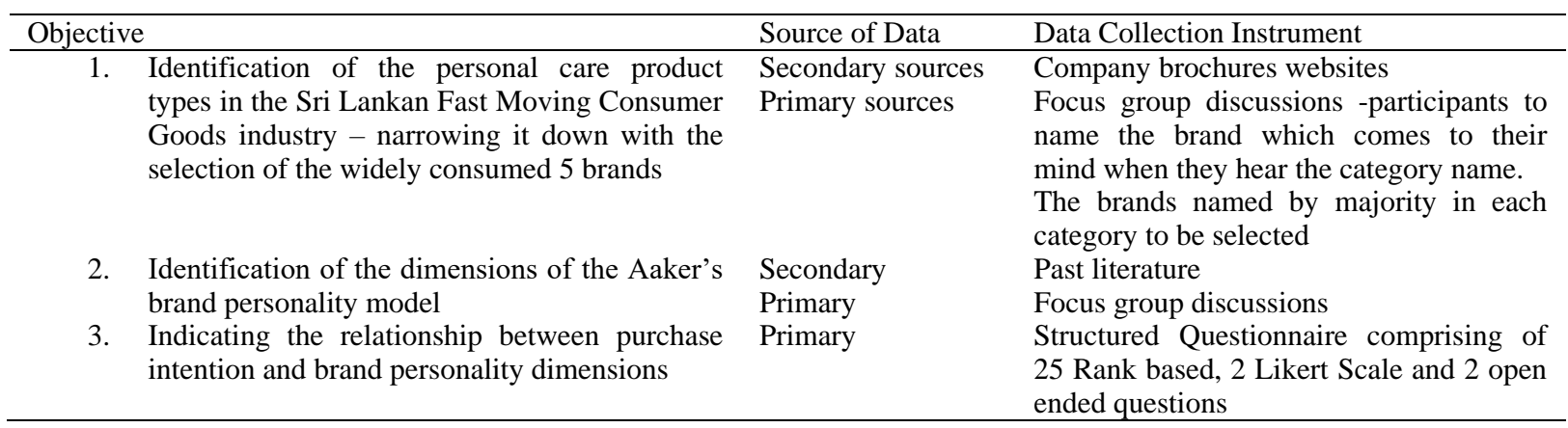

\section{Findings and Discussion}

\subsection{Results of the Focus Group Discussions}

With the use of the 3 focus group discussions conducted, the top of mind brand of the each personal care product category was identified and listed down. These focus groups discussions which lasted for about 45 minutes each were capable of providing the researcher with an understanding of the insights of the personal care product consumers. Accordingly, the top of mind brand identified from each category is listed below

- Hair care- Sunsilk brand manufactured by Unilever Sri Lanka

- Skin care- Vaseline brand manufactured by Unilever Sri Lanka 
- Oral care - Signal brand manufactured by Unilever Sri Lanka

- Cosmetics - Lakme brand marketed by Unilever Sri Lanka

- Fragrances - Rexona brand manufactured by Unilever Sri Lanka

In terms of identifying the top of mind brand, the participants were explained about the product category without any indication of the brands and was asked to name the brand name that comes to their mind when they hear the category name. The brands were finalized based on the number of times it was repeated by the customers when the question was asked. An interesting finding was the fact that all the brands picked by the majority were manufactured by Unilever Sri Lanka.

The other significant findings of the focus group discussions was about the importance that these participants held for the personal care brands in terms of it reflecting g their personality. The participants believed that they prefer and would undoubtedly choose those brands which they could closely associate with their personality over the other options. Hence, the findings of the literature survey was confirmed via this as well.

\subsection{Results of the Survey}

Those findings were then used to design the structured questionnaire that firmly targeted upon identifying the most appropriate personality dimension to be reflected in each of the chosen brand. Once the data was gathered it was analyzed through statistical techniques. Kruskal-Wallis $\mathrm{H}$ test is a rank-based nonparametric (distribution free) test which is used to determine whether there are statistically significant differences between two or more groups of an independent variable on a continuous or ordinal dependent variable (McDonald, 2014). Simply, it compares the identified groups of the independent variable based on the mean ranks. The SPSS output provides a mean rank which considers this type of data as "K Independent Samples". This test also provides the "Chi-square test statistic" which determines whether there is a relationship between the independent and the dependent variable through alpha error rate or level of significance.

Kruskal-Wallis $\mathrm{H}$ test was then followed by "Nemenyi post hoc test" to distinguish between the independent variable groups. To distinguish between different personality dimensions, the mean rank differences were calculated and those differences between personality dimensions are compared against the above calculated Minimum Significant Difference (MSD) value of 30.62. If the mean difference between a personality dimension pairs is greater than 30.62 , it is concluded that there is a significant difference between the consumer 'preferences towards a particular brand with the inclusion/association of those personality dimensions. If the value is less than 30.62, it is concluded that there isn't a significant difference in the consumer's preference with the inclusion/association of the personality dimensions.

Accordingly the findings are as below for each of the selected brands,

4.2.1 Lakme

Table 2. Kruskal Walis H Test Result for Lakme

\begin{tabular}{llll}
\hline & Personality Dimension & N & Mean Rank \\
\hline Score & Sincerity & 100 & 231.50 \\
& Excitement & 100 & 244.50 \\
& Competence & 100 & 280.50 \\
& Sophistication & 100 & 285.50 \\
& Ruggedness & 100 & 210.50 \\
& Total & 500 & \\
\hline
\end{tabular}

According to Kruskal Wallis $\mathrm{H}$ test, it showed that there was a statistically significant difference in the consumer's preference towards Lakme brand with reference to different personality traits. According to mean rank scores, it is evident that Sophistication is ranked the highest while ruggedness is ranked as the lowest.

Nemenyi Post Hoc test results

Table 3. Mean differences for Lakme

\begin{tabular}{llllll}
\hline & Sincerity & Excitement & Competence & Sophistication & Ruggedness \\
\hline Sincerity & 0 & -13 & -49 & -54 & 21 \\
Excitement & 13 & 0 & -36 & -41 & 34 \\
Competence & 49 & 36 & 0 & -5 & 70 \\
Sophistication & 54 & 41 & 5 & 0 & 75 \\
Ruggedness & -21 & -34 & -70 & -75 & 0 \\
\hline
\end{tabular}

Out of the values that exceed the MSD value of 30.62, is that of the Sophistication/ Ruggedness pair which has the biggest difference of 75 . Therefore, it can be stated that there is a significant difference in consumer's 
preference towards Lakme brand with the inclusion of a promotional message which has sophistication dimension and ruggedness dimension.

\subsubsection{Rexona}

Table 4. Kruskal Walis H Test Result for Rexona

\begin{tabular}{llll}
\hline & Personality dimension & $\mathrm{N}$ & Mean Rank \\
\hline Score & Sincerity & 100 & 240.01 \\
& Excitement & 100 & 274.33 \\
& Competence & 100 & 288.42 \\
& Sophistication & 100 & 238.05 \\
& Ruggedness & 100 & 211.70 \\
& Total & 500 & \\
\hline
\end{tabular}

According to Kruskal Wallis $\mathrm{H}$ test, it showed that there was a statistically significant difference in the consumer's preference towards Rexona brand with reference to different personality traits. According to mean rank scores, it is evident that Competence is ranked the highest while ruggedness is ranked as the lowest.

Nemenyi Post Hoc test results

Table 5. Mean differences for Rexona

\begin{tabular}{llllll}
\hline & Sincerity & Excitement & Competence & Sophistication & Ruggedness \\
\hline Sincerity & 0 & -34.32 & -48.41 & 1.96 & 28.31 \\
Excitement & 34.32 & 0 & -14.09 & 36.28 & 62.63 \\
Competence & 48.41 & 14.09 & 0 & 50.37 & 76.72 \\
Sophistication & -1.96 & -36.28 & -50.37 & 0 & 26.35 \\
Ruggedness & -28.31 & -62.63 & -76.72 & -26.35 & 0 \\
\hline
\end{tabular}

Out of the values that exceed the MSD value of 30.62, is that of the Competence/ Ruggedness pair which has the biggest difference of 76.72. Therefore, it can be stated that there is a significant difference in consumer's preference towards Rexona brand with the inclusion of a promotional message which has competence dimension and ruggedness dimension.

4.2.3 Signal

Table 6. Kruskal Walis H Test Result for Signal

\begin{tabular}{llll}
\hline & Personality dimension & $\mathrm{N}$ & Mean Rank \\
\hline Score & Sincerity & 100 & 296.50 \\
& Excitement & 100 & 280.50 \\
& Competence & 100 & 311.50 \\
& Sophistication & 100 & 194.50 \\
& Ruggedness & 100 & 169.50 \\
& Total & 500 & \\
\hline
\end{tabular}

According to Kruskal Wallis $\mathrm{H}$ test, it showed that there was a statistically significant difference in the consumer's preference towards Signal brand with reference to different personality traits. According to mean rank scores, it is evident that Competence is ranked the highest while ruggedness is ranked as the lowest.

Nemenyi Post Hoc test results

Table 7. Mean differences for Signal

\begin{tabular}{|c|c|c|c|c|c|}
\hline & Sincerity & Excitement & Competence & Sophistication & Ruggedness \\
\hline Sincerity & 0 & 16 & -15 & 102 & 127 \\
\hline Excitement & -16 & 0 & -31 & 86 & 111 \\
\hline Competence & 15 & 31 & 0 & 117 & 142 \\
\hline Sophistication & -102 & -86 & -117 & 0 & 25 \\
\hline Ruggedness & -127 & -111 & -142 & -25 & 0 \\
\hline
\end{tabular}

Out of the values that exceed the MSD value of 30.62, is that of the Competence/ Ruggedness pair which has the biggest difference of 76.72. Therefore, it can be stated that there is a significant difference in consumer's preference towards Signal with the inclusion of a promotional message which has competence and ruggedness dimensions. 


\subsubsection{Vaseline}

Table 8. Kruskal Walis H Test Result for Vaseline

\begin{tabular}{llll}
\hline & Personality Dimension & N & Mean Rank \\
\hline Score & Sincerity & 100 & 313.50 \\
& Excitement & 100 & 284.50 \\
& Competence & 100 & 288.50 \\
& Sophistication & 100 & 215.50 \\
& Ruggedness & 100 & 150.50 \\
& Total & 500 & \\
\hline
\end{tabular}

According to Kruskal Wallis $\mathrm{H}$ test, it showed that there was a statistically significant difference in the consumer's preference towards Vaseline with reference to different personality traits. According to mean rank scores, it is evident that Sincerity is ranked the highest while ruggedness is ranked as the lowest.

Nemenyi Post Hoc test results

Table 9. Mean differences for Vaseline

\begin{tabular}{llllll}
\hline & Sincerity & Excitement & Competence & Sophistication & Ruggedness \\
\hline Sincerity & 0 & 29 & 25 & 98 & 163 \\
Excitement & -29 & 0 & -4 & 69 & 134 \\
Competence & -25 & 4 & 0 & 73 & 138 \\
Sophistication & -98 & -69 & -73 & 0 & 65 \\
Ruggedness & -163 & -134 & -138 & -65 & 0 \\
\hline
\end{tabular}

Out of the values that exceed the MSD value of 30.62, is that of the Sincerity/ Ruggedness pair which has the biggest difference of 76.72. Therefore, it can be stated that there is a significant difference in consumer's preference towards Vaseline brand with the inclusion of a promotional message which has Sincerity and ruggedness dimensions.

4.2.5 Sunsilk

Table 10. Kruskal Walis H Test Result for Sunsilk

\begin{tabular}{llll}
\hline & Personality dimension & N & Mean Rank \\
\hline Score & Sincerity & 100 & 268.50 \\
& Excitement & 100 & 298.50 \\
& Competence & 100 & 285.50 \\
& Sophistication & 100 & 239.50 \\
& Ruggedness & 100 & 160.50 \\
& Total & 500 & \\
\hline
\end{tabular}

According to Kruskal Wallis $\mathrm{H}$ test, it showed that there was a statistically significant difference in the consumer's preference towards Sunsilk with reference to different personality traits.

According to mean rank scores, it is evident that Excitement is ranked the highest while ruggedness is ranked as the lowest.

Nemenyi Post Hoc test results

Table 11. Mean differences for Sunsilk

\begin{tabular}{|c|c|c|c|c|c|}
\hline & Sincerity & Excitement & Competence & Sophistication & Ruggedness \\
\hline Sincerity & 0 & -30 & -17 & 29 & 108 \\
\hline Excitement & 30 & 0 & 13 & 59 & 138 \\
\hline Competence & 17 & -13 & 0 & 46 & 125 \\
\hline Sophistication & -29 & -59 & -46 & 0 & 79 \\
\hline Ruggedness & -108 & -138 & -125 & -79 & 0 \\
\hline
\end{tabular}

Out of the values that exceed the MSD value of 30.62, is that of the Excitement/ Ruggedness pair which has the biggest difference of 76.72. Therefore, it can be stated that there is a significant difference in consumer's preference towards Sunsilk brand with the inclusion of a promotional message which has Excitement and ruggedness dimensions.

\section{Conclusion}

Brand personification is one such area which is concerned with humanizing a brand in to a human-like character. Being such an interesting area, the importance of associating the suitable human-based personality that goes in line with the brand image is of utmost importance in designing communications. Thus, based on it, the research study was focused upon the identification of the most suitable personality dimension to be implicated in each of the selected personal care brand being selected. With reference to the personal care product categorizations, Siganal, Lakme, Vaseline, Rexona, and Sunsilk were identified as the Top of Mind Brands within the personal 
care product consumers.

According to the discussions carried out with the same, it was also evident that the consumers prefer to see a reflection of themselves in the personal care products that they consumer. Hence, they get attracted towards the brand if such reflection exists. Those consumers prefer to see personalities such as the down to earth humble nature, and willingness to try out new things, the capability to do something successfully and the upper-class related mentality in them. The consumers does not prefer the masculine nature to be prevalent in any of those products they consume.

With reference to the identification of the most suitable dimension to be associated with each brand, Kruskal-Wallis $\mathrm{H}$ test was followed by Nemeneyi Post Hoc test to distinguish among the perceived differences in preference among different dimensions. Accordingly, it was revealed that Competence was the preferred dimension for Rexona and Signal, Sophistication was preferred for Lakme. Sincerity was the preferred dimension for Vaseline while Excitement was preferred fir Sunsilk.

On a concluding note it can be noted that, brand personification is becoming increasingly attractive in the context of marketing communications, but the need of identifying and applying the proper humanizing aspect is of utmost importance to make the promotion attractive and appealing.

\section{Managerial Implications and Recommendations for Future Research}

With reference to the findings of the study, the following personality dimensions can be recommended to be highlighted in their promotions for the selected brands. Lakme is a brand which should be associated with a high class personality, while Rexona and Signal are viewed as brands which should reflect the success or capability of the brand itself. Vaseline is recommended to be associated with a down to earth, humble nature while Sunsilk can be associated with innovativeness and excited nature. It is also recommended not to associate masculine, rough nature to these brands since the female consumers does not prefer it at all.

In terms of the recommendation for the future research studies, it is better if the moderating effect is also taken in to account. Due to the inability of dealing with a wide scope the moderating impact hasn't been considered. As explained in literature, a moderating impact through adding a variable such as and endorser or communication media can be tested through future researches.

\section{References}

Aaker, J. L. (1997). Dimesnions of Brand Personality. Journal of Marketing Research, 34, 347-356. https://doi.org/10.1177/002224379703400304

Banerjee, S. (2016). Influence of consumer personality, brand personality, and corporate personality. Asia Pacific Journal of Marketing and Logistics, 28, 198-216. https://doi.org/10.1108/APJML-05-2015-0073

Bensi, P. (2015). Linkedin. Retrieved October 11, 2016, from https://www.linkedin.com/pulse/5-successful-examples-brand-personification-patrick-bensi

Cooray, S. (2016). Spend on Marketing Communication activities.

Dolatabadi, H. R., Kazemi, A., \& Rad, S. N. (2012). The Impact of Brand Personality on Product Sale through Brand Equity (Case Study: Cosmetic Products Retailers). International Journal of Academic Research in Business and Social Sciences, 2(2), 294-309.

Gupta, V. (2013). A study on Consumer perception and Brand Personality. GYANPRATHA - ACCMAN Journal of Management, 5(1).

He, J. (2012). Sincerity, excitement and sophistication: The different effects of perceived brand. Nankai Business Review International, 3, 398-412. https://doi.org/10.1108/20408741211283746

Jin Su, X. T. (2014). Exploring the personality of sportswear brands. Sport, Business and Management: An International Journal, 4(2), 178-192. https://doi.org/10.1108/SBM-08-2012-0032

Maehle, N., \& Shneo, R. (2010). On congruence between brand and human. Journal of Product \& Brand Management, 19, 44-53. https://doi.org/10.1108/10610421011018383

Maehle, N., \& Shneor, R. (2009). "On Congruence between Brand and Human Personalities". Journal of Product and Brand Management, 19(1), 44-53. (ISSN 1061-0421). https://doi.org/10.1108/10610421011018383

McDonald, J. H. (2014). Kruskal Wallis Test. In Handbook of Biological Statistics (pp. 157-164). Baltimore, Maryland: Sparky House Publishing.

Monger, B. (2012, May 30). The Personality of Brands -Using Effective Brand Personality to Grow Your 
Business. Retrieved 02 2017, 15, from

https://smartamarketing.wordpress.com/2012/05/30/the-personality-of-brands-using-effective-brand-person ality-to-grow-your-business/

Mulyanegara, R. C., Tsarenko, Y., \& Anderson, A. A. (2009). The Big Five and brand personality: Investigating the impact of consumer personality on preferences towards particular brand personality. Journal of Brand Management, 16(4), 234-247. https://doi.org/10.1057/palgrave.bm.2550093

Plummer, J. T. (1984). How personality makes a difference. Journal of Advertising Research, 24(6), 27-31.

Santos, W. D. (2014). Linkedin. Retrieved 10 07, 2016, from

https://www.linkedin.com/pulse/20140306031629-11082999-the-five-dimensions-of-brand-personality

The Central Bank of Sri Lanka. (2017). Economic and Social Statistics of Sri Lanka. Colombo: The Central Bank of Sri Lanka.

The Nielsen Company. (2017). SRI LANKA: 2013 REVIEW AND OPPORTUNITIES IN 2014.

\section{Copyrights}

Copyright for this article is retained by the author(s), with first publication rights granted to the journal.

This is an open-access article distributed under the terms and conditions of the Creative Commons Attribution license (http://creativecommons.org/licenses/by/4.0/). 